\title{
IMPROVEMENT IN MAGNETIC PROPERTIES OF COZrNb THIN FILMS FOR A SINGLE POLE TYPE HEAD
}

\author{
Hiroshi YOKOTA , Ichiro KUDAKA , Masami YAMASHITA and Terutoshi SUENAGA \\ Research Center, Denki Kagaku Kogyo K.K. \\ 3-5-1 Asahicho, Machidashi , Tokyo 194, Japan
}

\begin{abstract}
The read/write performance of a single pole type head was greatly advanced by increasing the magnetic circuit efficiency . These developments have enabled recording densities of $530 \mathrm{Mb} / \mathrm{in}^{2}$ without $\mathrm{MR}$ and PRML technology . In order to achieve higher recording density, we have investigated CoZrNb films deposited by ion beam sputtering . It is confirmed that an increase of the amount of incident particles with a large incident angle leads to improve the magnetic properties of CoZrNb films in the thickness range less than $2000 \AA$.

Keywords ; Perpendicular magnetic recording, Contact recording, Single pole type head, CoZrNb film
\end{abstract}

\section{INTRODUCTION}

In the eariler work, we reported a contact single pole type head , of which the fundamental concept is employed in the original Salanx Head . However, its signal amplitude at $100 \mathrm{kfci}$ was only $80 \mathrm{nV} V_{\mathrm{pp}} / \mu \mathrm{m} / \mathrm{turn} / \mathrm{m} / \mathrm{s}$ which is too low for practical application [1] . The low amplitude seemed to be caused by the low reproducing effciency of its transducers .

We tried to improve the efficiency this time. The geometry of the transducsers such as the return stud(R.S.) or the back gap(B.G.) was analyzed using a micromagnetic calculation software(JMAG) first .

As the R.S. functions only to gather the return flux up , area(thickness) of the R.S. facing toward the recording media should be large(wide). Our calculation results also suggested this trend. However, the amplitude increase is saturated when the thickness is over $40 \mu \mathrm{m}$. The B.G. thickness(length between the main pole and the R.S.) seems to influence the reproducing efficiency because the B.G. induces an electric current in a coil by magnetic flux change. The calculation results say that the signal amplitude increases with the decrease of the B.G. thickness, but that a peak -shift occurs when the B.G. is too thin and then the desireble thickness of the B.G. is 25 to $30 \mu \mathrm{m}$.

In order to confirm the calculation result, transducers of the Salanx Head were refabricated as shown in Table 1, and read/write characteristics were examined . $\mathrm{A} \mathrm{CoZrNb}$ film for the main pole and NiFe films for the R.S. and the B.G. were deposited on the same condition as our previous work. The read/write characteristics were measured with a double layered medium composed of a $700 \AA$ thick $\mathrm{CoCrTa}(\mathrm{Hc}: 2700 \mathrm{Oe})$ and a $7 \mu \mathrm{m}$ thick $\mathrm{NiFe}$.

Fig.1 shows its results. The signal amplitude of the new Salanx Head is $250 \mathrm{nV}_{\mathrm{pp}} / \mu \mathrm{m} / \mathrm{turn} / \mathrm{m} / \mathrm{s}$ at $100 \mathrm{kfci}$ and Pwso is $12 \mu "$. Conidering $5 \mu \mathrm{m}$ track width and a necessary guardband, track density reaches 4000 TPI and the new Salanx Head can actualize $530 \mathrm{Mb} / \mathrm{in}^{2}$ recording density with conventional peak detection at a linear velocity of $4 \mathrm{~m} / \mathrm{s}$.

Table 1 Specification of Salanx Head

\begin{tabular}{lccc}
\hline & Old design & New design \\
Pole material & Cos $Z \mathrm{ZrN}_{5} \mathrm{Nb}_{13}$ & $\leftarrow$ & \\
Pole thickness & $0.2 \mu \mathrm{m}$ & 0.18 & $\mu \mathrm{m}$ \\
Track width & $5.0 \mu \mathrm{m}$ & $\leftarrow$ & \\
Number of coil turns & 40 & $\leftarrow$ & \\
R.S. thickness & $10 \mu \mathrm{m}$ & 40 & $\mu \mathrm{m}$ \\
B.G. thickness & $15 \mu \mathrm{m}$ & 25 & $\mu \mathrm{m}$ \\
\hline
\end{tabular}

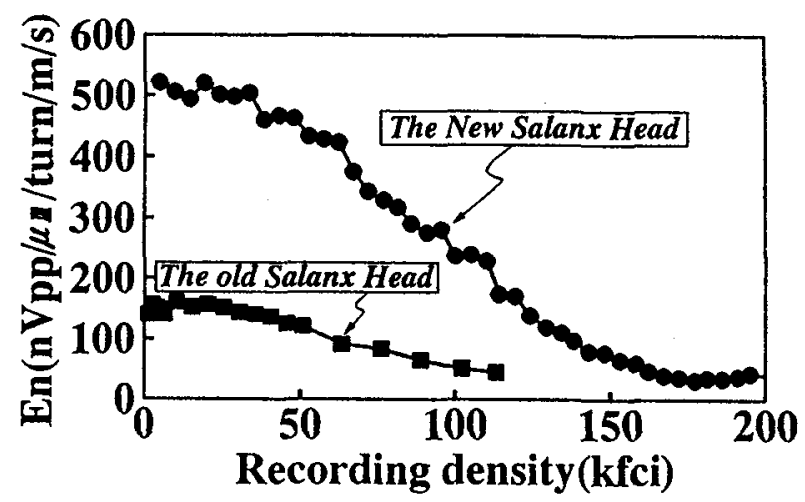

Fig.1 Recording density of the New Salanx Head

We confirmed that much of this advance in the $\mathrm{read} / \mathrm{write}$ characteristics was obtained by increasing the magnetic circuit efficiency . However, in order to achieve higher density recording, over $1 \mathrm{~Gb} / \mathrm{in}^{2}$, it is necessary to obtain high read -sensitivity with a thinner main pole film and a narrow track head . [2] To realize it, amorphous $\mathrm{CoZrNb}$ films which are deposited by ion beam sputtering were introduced as the material of main pole films .

However, magnetic properties of $\mathrm{Co}(\mathrm{Zr}, \mathrm{Nb}, \mathrm{Ta}, \mathrm{Mo})$ films are severely influenced by the film thickness, especially the coercivity increases with the decreasing of 
film thickness $[3,4]$. Therefore, it is difficult to obtain a thin main pole film with low coercivity. On the other hand, a closure domain areas tend to increase with narrowing track width [5] , and then it is dificult to control the domain structures .

We investigated the soft magnetic properties of $\mathrm{CoZrNb}$ films deposited by ion beam sputtering in the thickness range $500 \sim 2000 \AA$ in order to use them as very thin main pole heads. We present here relationships among sputtering conditions, magnetic properties , domain configuration, and microstructure of those films .

\section{IMPROVEMENT IN CoZrNb MAGNETIC PROPERTIES}

\section{A. EXPERIMENTAL}

An ion beam sputtering system is shown schematically in Fig. 2 . In order to obtain high rate deposition, a substrate is usually held parallel to the target. Since it is well known through some experimental results that magnetic properties are severely influenced by the substrate tilt angle. Therefore, $500 \sim 2000 \AA$ thick $\mathrm{CoZnNb}$ films were deposited on glass substrates with different tilt angles. The deposition was carried out in a 300 Oe field which is parallel to the substrate to induce uniaxial anisotropy in the films. The sputtering conditions are shown in Table 2 . The coercivities of the $\mathrm{CoZrNb}$ films were measured with a B-H curve tracer. The magnetostriction coefficient were measured by applying stress in parallel to the hard axis of the films . Chemical compositions of these films were analyzed with E.D.X. Internal stress of the films was measured by monitoring the change of curvature of the substrate before and after film deposition .

Table 2 Sputtering conditions
Target(wt\%)

Accelerative voltage

Background pressure

Ar pressure

Substrate temperature

Substrate tilt angle
$\mathrm{Co}_{5} \mathrm{Zr}_{5} \mathrm{Nb}_{10}, \mathrm{Co}_{3} \mathrm{Zr}_{4} \mathrm{Nb}_{3}$

$1 \mathrm{kV}$

less than $7 \times 10^{-7}$ Torr

$2.2 \times 10^{-4}$ Torr

$15{ }^{\circ} \mathrm{C}$

33,43 and $57 \mathrm{deg}$.
The domain structures of the CoZrNb films, patterned as a main pole shape of $3 \sim 25 \mu \mathrm{m}$ track width after at $180{ }^{\circ} \mathrm{C}$ in a $1 \mathrm{kOe}$ rotating field annealing and at $240{ }^{\circ} \mathrm{C}$ in a $1.4 \mathrm{kOe}$ static field annealing, were obsereved by Bitter method.

\section{B. RESULTS}

\section{Soft magnetic properties}

The film coercivity of the hard axis in as a function of the tilt angle is shown in Fig. 3 , while Fig. 4 shows B-H curves of sheet films deposited at $57^{\circ}$ and $33^{\circ}$

These data show that the coercivity of $\mathrm{CoZrNb}$ films prepared using both of targets Co85 $\mathrm{Zr}_{5} \mathrm{Nb}_{10}$ and $\mathrm{Co}_{3} \mathrm{Zr}_{4} \mathrm{Nb}_{3}$ can be reduced by increasing the tilt angle from $33^{\circ}$ to $57^{\circ}$. However, the deposition rate decreases when the tilt angle becomes larger.

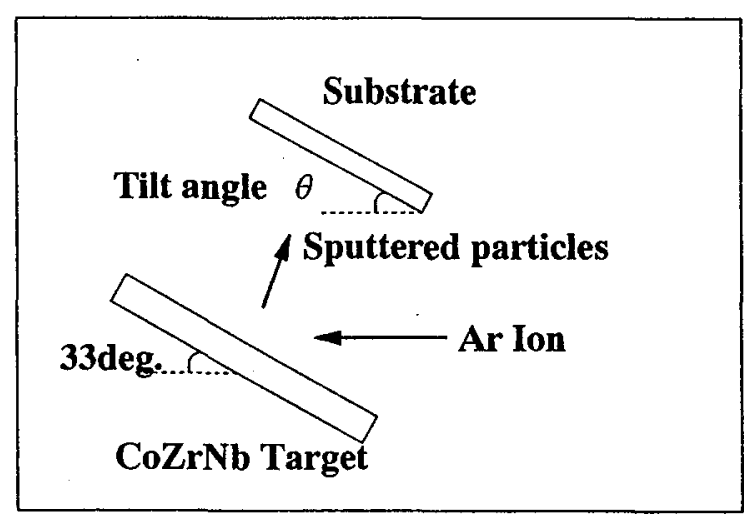

Fig. 2 Ion beam sputtering machine for deposition

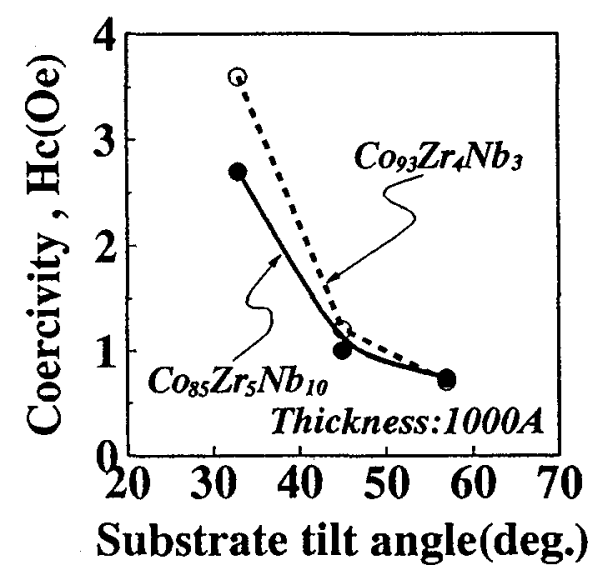

Fig. 3 Coercivity as a function of the substrate tilt angle

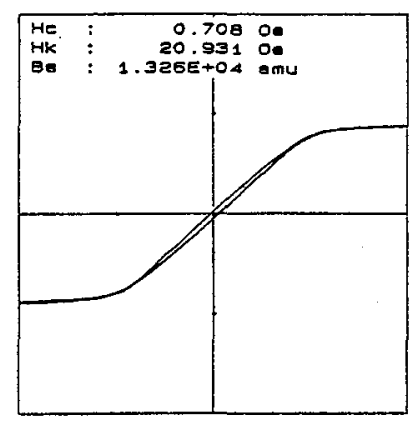

Tilt angle : $57 \mathrm{deg}$.

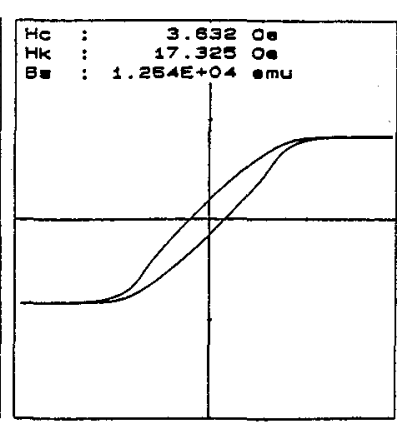

Tilt angle : $33 \mathrm{deg}$.
Fig. 4 B-H curve of as deposited $\mathrm{C}_{0} \mathrm{Zr}_{4} \mathrm{Nb}_{3}$ films 


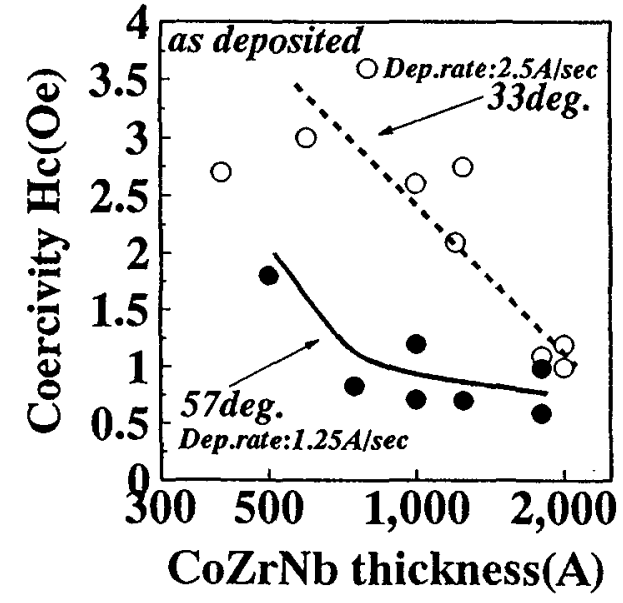

Fig. 5 Coercivity dependence on $\mathrm{CoZ}$ rNb thickness

Fig. 5 shows the relationship coercivity and thickness of $\mathrm{CoZrNb}$ which were deposited at $33^{\circ}$ and $57^{\circ}$. The data show the coercivity decreases as the film becomes thinner. However, the coercivity of films deposited at 57 ${ }^{\circ}$ increases less than those of deposited at $33^{\circ}$.

Fig.6 shows the magnetostriction coefficients as a function of the substrate tilt angle. The magnetostriction coefficient shifts from positive to negative when the angle becomes larger. However, the values deposited at $43^{\circ}$ and $57^{\circ}$ are within the order of $10^{-7}$.

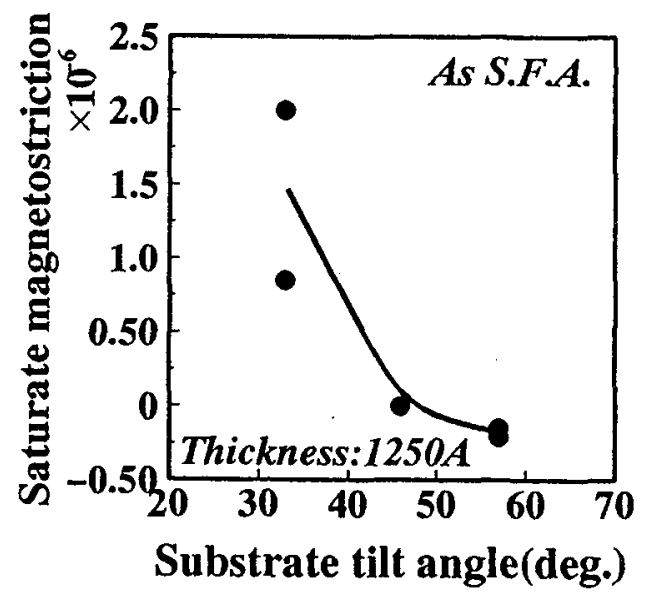

Fig.6 Saturate magnetostriction

\section{Domain structure}

Fig. 7 shows a relationship between the effective track width [5] and the patterned track width. The effective track width with negative magnetostriction is wider than that with positive magnetostriction when the track width is less than approximately $10 \mu \mathrm{m}$ in spite of the same anisotropy field of $12 \mathrm{Oe}$.

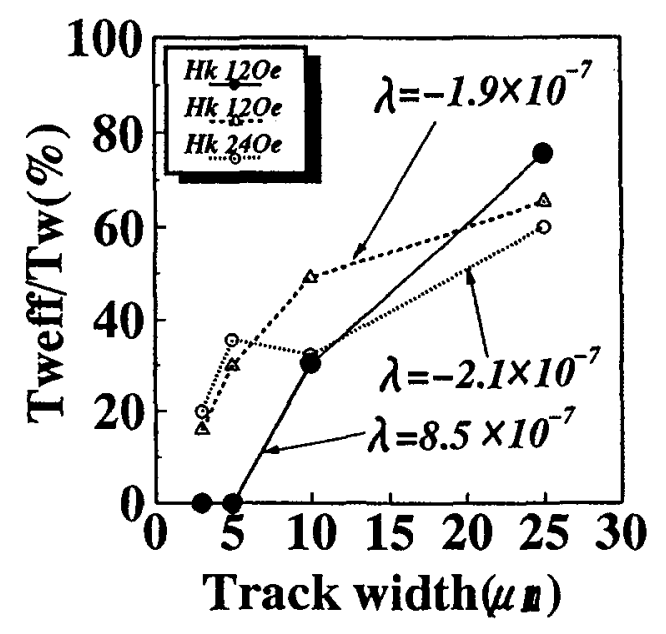

Fig. 7 Dependence of the effective track width on the pattern width

\section{DISCUSSION}

\section{Improvement in soft magnetic properties}

In this experiment, we succeeded in preparing a 1000 $\AA$ thick CoZrNb film with a low coercivity of $1 \mathrm{Oe}$, and confirmed that the deposition rate of $\mathrm{CoZrNb}$ films decreased when the substrate tilt angle are large. Then it seems that such good magnetic properties have been attained by the low deposition rate . In order to confirm this effect, we have also investigated the relationship between the magnetic properties and deposition rate.

However, we could not obtain any low coercivity $\mathrm{CoZrNb}$ films of $1 \mathrm{Oe}$ or less by deposition at $33^{\circ}$, although it was done at the same low rate of $1.25 \AA / \mathrm{sec}$ as the deposition at $57^{\circ}$ by adjusting the ion current to the target during deposition .

Another possibility is that the low coercivity $\mathrm{CoZrNb}$ films may have been obtained by oblique incidence deposition. In order to confirm this hypothesis, cross sections of CoZrNb films were observed .

Fig.8 shows a T.E.M. images of the films deposited at $57^{\circ}$ and $33^{\circ}$ of substrate tilt angle. The film at $57^{\circ}$ has a columnar structure, and while the film at $33^{\circ}$ does not exhibit any microstructure .

On the other hand, it was found that the internal stress of the film deposited at $57^{\circ}$ is lower than that of at $33^{\circ}$ as shown in Fig.9.

According to these results, the CoZrNb film of the columnar structure seems to be caused by the oblique incidence of sputtering particles. It appears that the columnar structure is attribute to stress relaxation of the $\mathrm{CoZrNb}$ film . 


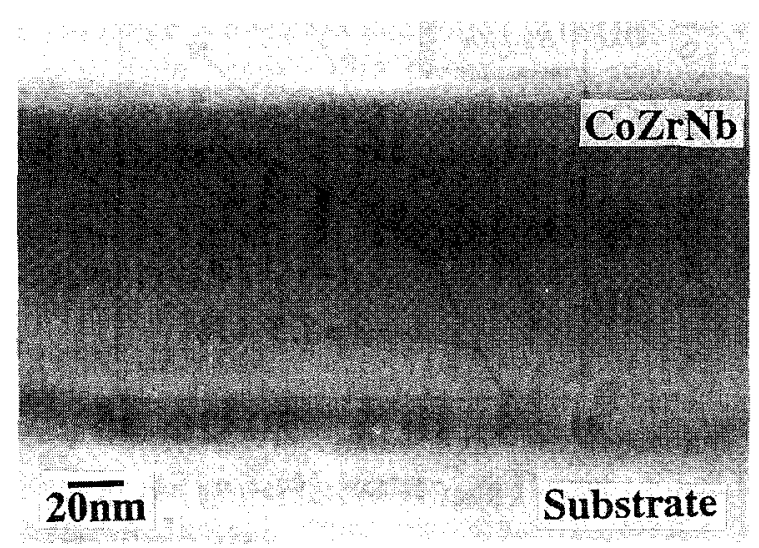

(a) Tilt angle : $57^{\circ}$

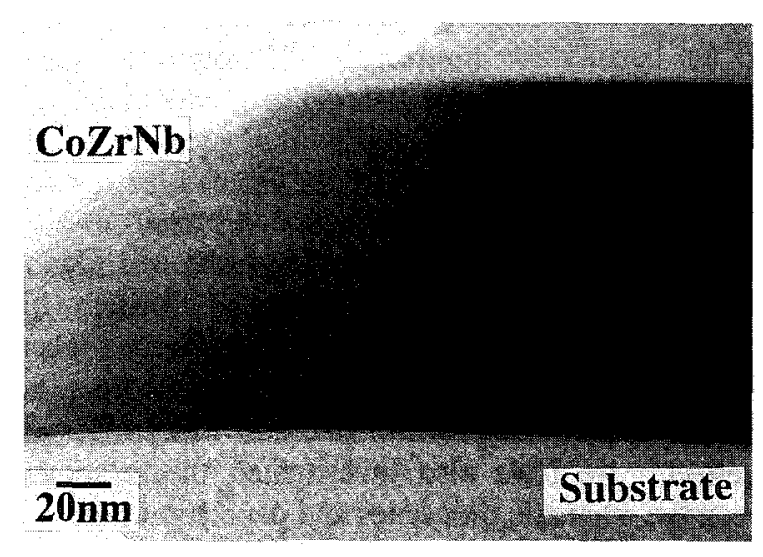

(b) Tilt angle : $33^{\circ}$

Fig.8 T.E.M. photographs for CoZrNb films

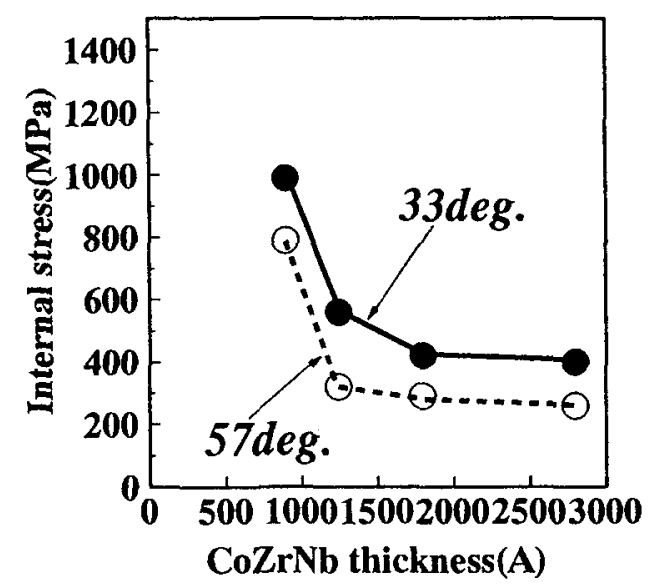

Fig. 9 Dependence of the internal stress on $\mathrm{CoZrNb}$ thickness
The work of Kersten shows that the coercivity of $\mathrm{Ni}$ decreases as the internal stress of Ni decreases . [6] The similar result is described by Naoe et.al about sputtered Fe film . [7]

According to these results, in this study the oblique incidence deposition is attributed to stress relaxation of the $\mathrm{CoZrNb}$ film, as a result, the low coercivity $\mathrm{CoZrNb}$ film may be obtained. However, the exact reason for relationship between internal stress and film thickness is not clear

\section{CONCLUSION}

An increase in the amount of the high angle incident particles leads to improve magnetic properties of ion beam sputtered $\mathrm{CoZrNb}$ films with thickness than $2000 \mathrm{~A}$. And good domain structure with negative magnetostriction in a narrow track of $3 \mu \mathrm{m}$ can be expected.

\section{ACKNOWLEDGEMENT}

The authors would like to acknowledgement I.Sugimoto for T.E.M. observation .

\section{REFERENCES}

[1] H.Yokota , M.Yamashita , N.Nakazaki and T.Suenaga " Development of a single pole type head " Journal of the magnetics society of Japan vol.17 Suplement No.S2 , pp216-221 , 1993 (in Japanese)

[2] M.Otagiri , H.Muraoka , I. Watanabe and Y.Nakamura " Domain configuration effect of a thin main pole film for SPT heads " Journal of the magnetics society of Japan vol.17 Suplement No.S2 , pp216-221 , 1993 (in Japanese) [3] K.Yamada , T.Maruyama , M.Ohmukai and H.Urai " CoZrMo amorphous films as a soft adjacent layer for biasing magnetoresistive elements with a current shunt layer " Journal of Applied Physics 63 (8) , 15 , pp40234025,1988

[4] S.Nakagawa, S.Yoshida, T.Ichihara and M.Naoe

" Soft magnetic backlayer of amorphous CoZrTa for perpendicular magnetic recording media " Journal of the magnetics society of Japan vol.17 Suplement No.S2 , pp249-254, 1993 , (in Japanese)

[5] K.Yamakawa, Y.Nakamura and S.Iwasaki

" Effect of domain structure of main pole film on reproducing sesitivity of S.P.T. head " Journal of the magnetics society of Japan vol.9, pp79-82, 1985 (in Japanese)

[6] M.Kersten

Problem der tech , 1938

[7] M.Naoe , A. Kawano and A. Fukizawa

" Soft magnetic and rust proof properties of high purity iron sputtered films ."Technical report of the institute of electronics, information and communication engineers, MR 85-42, pp7-14 , 1985 (in Japanese ) 